\title{
HyperCard-Assisted Journal Article Filing System
}

\author{
Donald L. Renfrew
}

The author describes his own system of filing and accessing articles by means of a computerized representation of the articles. This system, using HyperCard stacks, provides an easy and quick method to store and retrieve useful articles.

(c) 1990 by W.B. Saunders Company.

KEY WORDS: HyperCard, Macintosh, journals, articles, filing system.

$\mathbf{T}$ he explosion of information in radiology and the lag time between the writing and the publishing of textbooks make it a virtual necessity for radiologists to develop and maintain article files. To be useful, it is necessary that the filer be able to access filed articles easily. Unfortunately, the same paper can often be filed logically in a number of categories, complicating article retrieval. Computers have been used to store journal article reference information. ${ }^{1,2}$ The purpose of this article is to describe a method of filing articles and an associated computerized representation of the articles filed. Because the computerized representation is easily searched, the user can, in a matter of seconds, access and retrieve an article.

\section{MATERIALS AND METHODS}

\section{Organization of the Article File}

Articles in the HyperCard system (created by the author) are filed within folders labeled according to the Index for Radiological Diagnosis. ${ }^{3}$ Initially, each folder contains articles from a single anatomic field (skull and contents; face, mastoids, and neck; etc). When a folder collects 30 articles, the folder is split. The Index recommends using only the first anatomy code number, and within that code using the pathology code numbers. This recommendation works well when filing articles such as "lung, mediastinum, and pleura" (field 6). In other fields, such as "skeletal system," (field 4), filing according to the first two anatomic field numbers works

From the Department of Radiology, College of Medicine, The University of Iowa, Iowa City, IA 52242.

Address reprint requests to Donald L. Renfrew, $M D$, Department of Radiology, College of Medicine, The University of Iowa, Iowa City, IA 52242.

The author will provide a copy of the HyperCard stack described in this report, minus the article representations, to anyone sending him a blank diskette.

( 1990 by W.B. Saunders Company.

0897-1889/90/0301/0009\$03.00/0 as well or better. When using two anatomic field numbers, anatomic field 0 , "location not specified or unknown," is eliminated, and the articles that might fall into this category are filed in anatomic field 8 , "more than one of the above, generalized."

Whether using one or two anatomy code numbers, the pathology code numbers are also entered. The same 30 article rule is employed to split folders. For example, if there are more than 30 articles on "arthritis of the hand," folders designated $43.71,43.72$, etc are created, and the articles are appropriately distributed in these folders.

Certain articles cannot be categorized by the ACR Index. These are filed by an accessory scheme which is listed in Table 1.

\section{Computer System and Software}

An Apple Macintosh II computer (Apple Computer, Cupertino, CA) with 1.0 Mbyte of random-access memory, an internal 800 -kbyte, 3.5 -in $(8.9 \mathrm{~cm})$ floppy drive, and an external 80-Mbyte hard drive (Direct Drive 80, Jasmine Technologies Inc, San Francisco, CA) were used. The software used was Apple HyperCard.

HyperCard acts as a gigantic table-top which holds piles of $3 \times 5$ cards. In HyperCard parlance, the piles are called "stacks," and the cards "cards." As with real $3 \times 5$ cards, there may be text, pictures, or both on the cards. The text comes in boxes called "fields" that may contain words or numbers. Logical operations (eg, sorting by alphabetical order, comparing for equality) can be performed on words, whereas nearly any arithmetic operation can be performed on numbers.

The text of the fields does not need to fit on the $3 \times 5$ cards: through use of what is called a "scroll box" (Fig I), words can be hidden from view on the card until the touch of a small arrow rolls the text through a window.

The true advantage of HyperCard lies in its "buttons." Buttons are areas of the $3 \times 5$ card that perform actions when "pushed" (actually, pushing the button on a mouse while the cursor is over the appropriate area on the card). The action taken is determined by what is called a "HyperTalk Script," which is a programming code. A button may create a new card, take the user to a different card, or draw a picture.

The computerized filing system uses a card (Fig 1) that has nine fields. Each card contains one of the following: the article title; at least the first three authors of the article; a journal citation; the institution of at least the first author; the American College of Radiology Index for Radiological Diagnosis code number (ACR number) or accessory code number; the abstract of the article; reader comments regarding the article; the date that the card was created; and a box indicating whether slides have been made from the article. The card also has four buttons. Two of these buttons shuffle through the stack one card at a time, either forward or backward. One of the buttons creates a new card for the stack and automatically fills in the "date" field. The fourth button takes the user back to the first card of the stack. 
Table 1. Accessory code numbers

\begin{tabular}{ll}
\hline 100 & Contrast \\
200 & Physics \\
300 & Statistics \\
400 & Education \\
500 & Computer \\
600 & Perception \\
700 & Editorials \\
800 & Medical economics \\
850 & Malpractice \\
900 & Reporting \\
\hline
\end{tabular}

The cards are divided into stacks depending on the scheme used in the article filing system. The stacks are accessed by using a card, with buttons, depicting the anatomic fields and "other articles," or articles that are filed by the accessory codes (Fig 2). Once in the appropriate anatomic field, another card (Fig 3) allows selection of the appropriate anatomic code number. This is the first card of all stacks within the anatomic field. In addition to allowing selection of other stacks in the anatomic field, these cards contain buttons to sort the articles of the stack by ACR number (or accessory number), the last name of the first author, the first author's institution, or the journal.

The user first decides on the stack in which the article is most likely to be filed. Next, the user uses the HyperCard "find" function by holding down a special key on the keyboard and depressing the letter " $F$." The find function requires the user to type in whatever word fragments he or she thinks might be on the card associated with the journal article he or she wants to find. If the user can remember the name of any of the first three authors, the institution, any terms in the abstract, or any pertinent comments, he or she then enters these words, or fragments of them, separated by spaces, into the find function. The find function is capable of searching through a thousand articles for a six-character fragment in less than five seconds, ${ }^{3}$ and will display the first card with the word fragments in any order, contained in any of the fields. If the first card displayed is not the card desired, the user hits the return key, and the next card with fields containing the desired word fragments will be displayed. Should this search fail, he or she may try a second one by entering slightly different word fragments.

To avoid the problem of ambiguity in filing, articles are filed according to the first ACR number listed in the ACR number field.

\section{DISCUSSION}

One of the prime disadvantages of this, or, indeed, any computerized filing system of reference management, is that one must somehow enter text material into the computer. Optical-

\begin{tabular}{|c|c|c|c|c|}
\hline \multirow{2}{*}{\multicolumn{2}{|c|}{$\begin{array}{l}\text { Article } \\
\text { Authors }\end{array}$}} & \multicolumn{3}{|c|}{$\begin{array}{l}\text { Sodium flouride treatment of osteoporosis: radiologic } \\
\text { findings }\end{array}$} \\
\hline & & \multicolumn{3}{|c|}{ El-Khoury GY, Moore TE, Albright JP et al } \\
\hline \multirow{2}{*}{\multicolumn{2}{|c|}{$\begin{array}{l}\text { Journal Citation } \\
\text { Institution(s) }\end{array}$}} & \multicolumn{3}{|l|}{ AJR 139:39-43, July 1982} \\
\hline & & 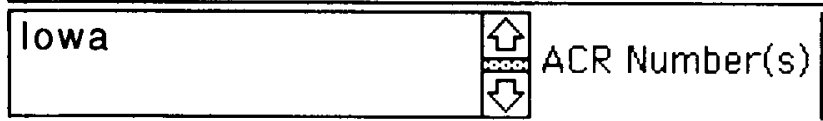 & 48.582 & \\
\hline $\begin{array}{l}\text { A } \\
\text { B } \\
\text { S } \\
\text { T } \\
\text { R } \\
\text { A } \\
\text { C } \\
\text { T }\end{array}$ & $\begin{array}{l}\text { Ten pe } \\
\text { before ar } \\
\text { were whi } \\
\text { developec } \\
\text { intoxicati } \\
\text { with incr }\end{array}$ & $\begin{array}{l}\text { atients with osteoporosis were studied } \\
\text { nd after treatment with fluoride. All } \\
\text { te and nine were women. The patients } \\
\text { d skeletal changes resembling flouride } \\
\text { on. This included pronounced bone de } \\
\text { eased number and thickness of trabec }\end{array}$ & \begin{tabular}{l|}
10 \\
ensity \\
ulae,
\end{tabular} & $\begin{array}{l}\text { New } \\
\text { Card }\end{array}$ \\
\hline $\begin{array}{l}C \\
0 \\
M \\
M \\
\text { E } \\
N \\
T \\
\text { S }\end{array}$ & $\begin{array}{l}\text { "The foll } \\
\text { generalize } \\
\text { of trabecu } \\
\text { obliteration } \\
\text { in the axi } \\
\text { "The me }\end{array}$ & $\begin{array}{l}\text { lowing skeletal changes were observed: } \\
\text { d increase in skeletal density; increased nur } \\
\text { lae; thickning of existing trabeculae; partial } \\
\text { n of the medullary space; and cortical thick } \\
\text { al skeleton." } \\
\text { echanism by which flouride acts on the skeletc }\end{array}$ & \begin{tabular}{l|l|l} 
mber \\
on is \\
kening
\end{tabular} & $\begin{array}{r}3 / 7 / 88 \\
\square 7\end{array}$ \\
\hline
\end{tabular}

Fig 1. Representative card. The rectangular boxes are fields; the horizontal arrows and boxes labeled "New Card" and "First Cord" are buttons. Scrolling arrows (vertical arrows at edges of bottom two fields) allow access to further text within the same field. 


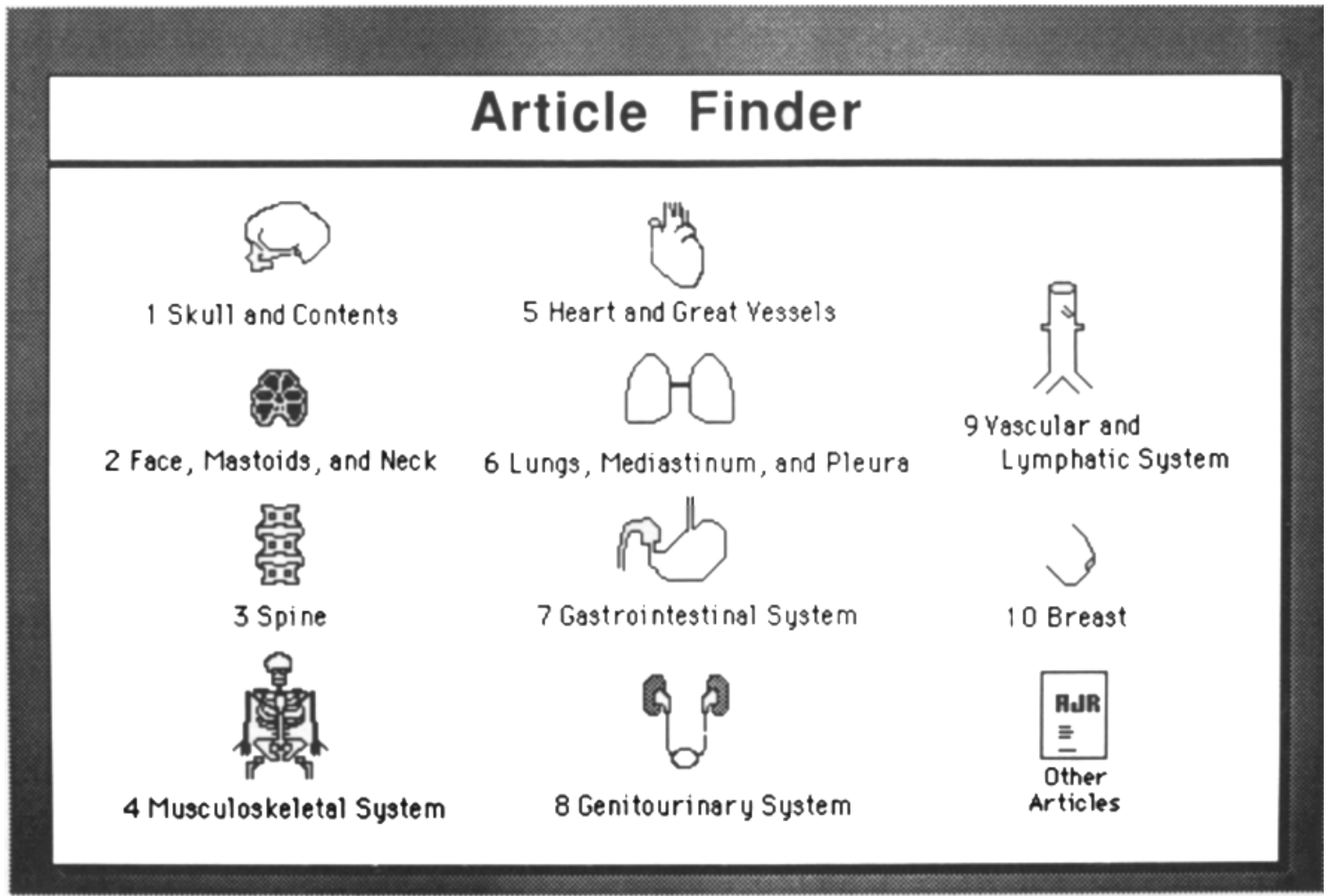

Fig 2. Card for selecting the anatomic code. Placing the cursor over the line drawing and pressing the mouse button takes the user to the appropriate anatomic area card.

character readers may one day provide a solution to this problem, but, at present, are too cumbersome to be practical. Proficient typists may find that typing in the abstract and comments regarding the article is not particularly time-consuming, and reinforces memory of the article. Others may prefer that a secretary perform this task. In either case, the more that is typed into each card, the more successful a user will be in later finding a particular article.

In addition to allowing a place for cursory evaluation of the article, the comments field may be used to mark certain articles; for example, if "study idea*" is entered into the comments field, the find function will stop at the card when "*study idea*" is searched.

This system does not provide for inclusion of a list of variably-formatted references, as do some others. $^{2}$

Although the system, in the overwhelming majority of cases, does allow the user to find an article it is not always successful. The computer does not know synonyms or equivalents. If the find function is using "ischemic necrosis" or "isch nec" and the card listing the article desired has "avascular necrosis" on it, the find function will not stop. Similarly, if the find function is using "MRI," it will not stop for a card with only "MR" on it. However, the find function will work in the converse situation, where it is looking for "MR" and the article title, abstract, or comments contains "MRI." A good rule of thumb is to use the shortest word fragment which does not result in stopping on virtually every card. "CT," for example, is in "fact" and "abstract," slowing searches with only "CT" in them. The goal of this system is not to perform searches of the medical literature; other programs, particularly those offering access to MEDLINE, such as MEDLARS, GRATEFUL MED, and SciMate, serve this purpose. ${ }^{2}$ Rather, the goal of this system is to allow an individual to retrieve an article that he or she has read and subsequently entered into the system. Such ready access can prevent much frustration when trying to find a vaguely recalled article, and can aid in both 


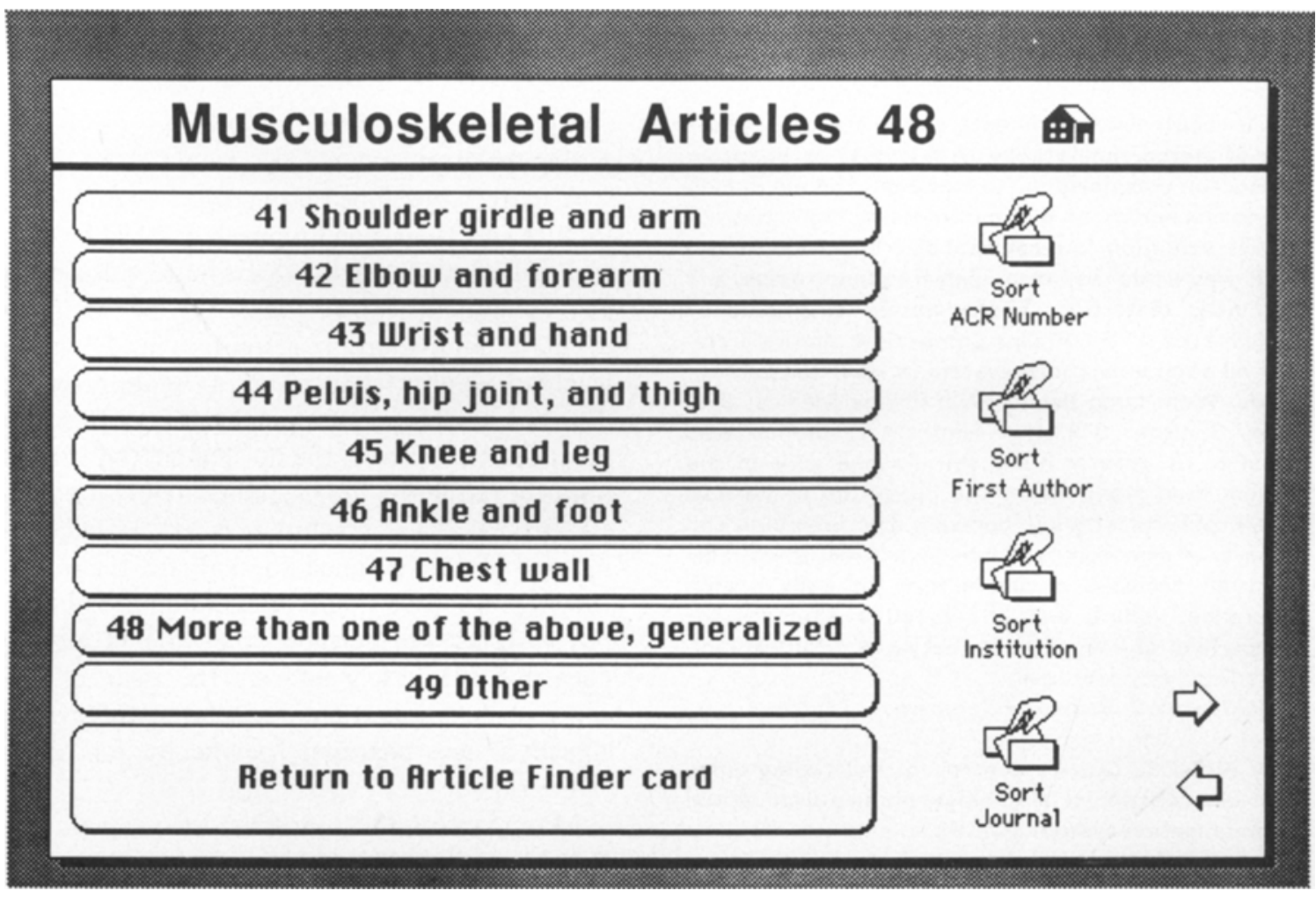

Fig 3. Card allowing access to cards representing articles filed in the musculoskeletal anatomic code. The oblong rectangles with rounded corners are buttons. Placing the cursor over the appropriate button and pressing on the mouse button takes the user to the indicated stack of cards.

patient care, through ready access to needed medical information, and teaching, through availability of articles for reading or copying.

There are commercially available programs which accomplish article filing. The main advantage of using a HyperCard system is its tremen- dously flexible application. The user may integrate the journal articles in to other stacks, modify not only text within fields but the fields themselves, and add buttons and graphics to cards as desired. This flexibility optimizes the future usefulness of the stored information.

\section{REFERENCES}

1. Hunter TB: Simple interactive computer program to store literature references. AJR 140:169, 1982

2. Gurney JW, Wigton RS: Computerized reference management-filing the literature. AJR 149:411-413, 1987
3. Goodman D: The two faces of HyperCard. MacWorld 1987, Oct, pp 122-129

4. American College of Radiology: Index for Radiological Diagnosis (ed 3, revised). Reston, VA, American College of Radiology, 1986 